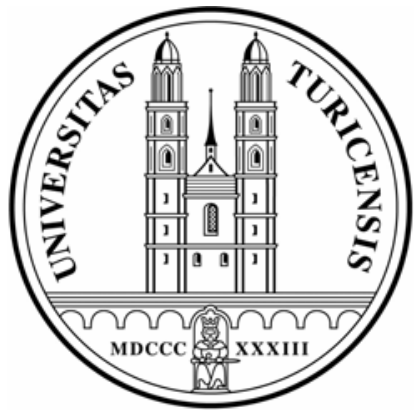

Institute for Empirical Research in Economics

University of Zurich

Working Paper Series

ISSN 1424-0459

Working Paper No. 313

Economics and Olympics: An Efficiency Analysis

Alexander Rathke and Ulrich Woitek

January 2007 


\title{
Economics and Olympics: An Efficiency Analysis *
}

\author{
Alexander Rathke ${ }^{\dagger}$ and Ulrich Woitek ${ }^{\ddagger}$ \\ Institute for Empirical Research in Economics, University of Zürich
}

January 2007

\begin{abstract}
Applying stochastic frontier analysis, we estimate the importance of sports in society as technical efficiency of countries in the production of Olympic success since the 1950s. Our measures of success are medal shares and a broader concept including Olympic diplomas. Following Bernard and Busse (2004), population and GDP are used as inputs. While the impact of GDP is always positive, we show that the sign of the population effect depends on wealth and population size of a country.

The results show that the spread of importance is very wide over time, across countries, gender, and sports. These differences can be seen as caused by differences in financial support, training methods, organization, or culture. Using the method proposed by Battese and Coelli (1995), we confirm the result well documented in the literature that planned economies and host countries are more successful than others in terms of Olympic success (e.g. Bernard and Busse, 2004). The method allows to shed light on important aspects of recent sport history, such as the consequences of the breakdown of the former Soviet Union.
\end{abstract}

Keywords: Olympic Games, Efficiency Analysis, Stochastic Frontier JEL: J8, O47

*We are grateful to Helmut Dietl, Wolfgang Köhler, Jim Malley, Rainer Winkelmann, conference participants at the EWEPA VIII, Brussels 2005, and seminar participants at the HUI Seminar 2006 for helpful comments and suggestions.

${ }^{\dagger}$ Corresponding author; address: Institute for Empirical Research in Economics, Economic History Section, University of Zurich, Winterthurerstr. 30, CH 8006 Zurich, phone: +41 44 634 3569, email: rathke@iew.unizh.ch.

¥Address: Institute for Empirical Research in Economics, Economic History Section, University of Zurich, Winterthurerstr. 30, CH 8006 Zurich, phone: +41 44634 3650, email: u.woitek@iew.unizh.ch. 
My friends and I have not been labouring at restoring you the Olympic Games in view of making them a fitting object for a museum or a cinema; nor is it our wish that mercantile or electoral interests should seize upon them. Our object in renovating an institution twenty-five centuries old, was that you should become new adepts of the religion of sports, such as our great ancestors had conceived it.

Pierre de Coubertin, 1927

\section{Introduction}

The Olympic Games have a long history. In 1892, Pierre de Coubertin organized the first modern Games at Athens, trying to revive the spirit of the ancient Olympic Games in Greece. ${ }^{1}$ Since then they have become the most important sporting event in the world. At the 2004 Games in Athens, 11,099 athletes, 5,500 team officials, and 21,500 members of the media attended. Athletes from 202 countries participated and around four billion people all over the world followed the Games on TV. The Games have also always been a stage for politics. Obvious examples are Berlin 1936, the Munich Massacre in 1972, and frequent politically motivated boycotts, especially the reciprocal boycotts of the East and the West at the Games in Moscow and Los Angeles.

The Olympic Charter (p. 16) states that "The Olympic Games are competitions between athletes in individual or team events and not between countries." Despite this idealistic statement and the IOC's refusal to recognize country rankings by medals, the medal table is updated on a realtime basis and plays a dominant role in media coverage and public interest.

What determines success at the Games? Factors affecting performance have been analyzed since the seminal study of the 1952 Olympic Games in Helsinki by Jokl et al. (1956). The best single predictor of Olympic success turns out to be GDP or GDP per capita, because GDP is a measure for available resources to train athletes, build and maintain training facilities, develop better training methods, etc. (e.g. Novikov and Maksimenko, 1973; Johnson and Ali, 2000;

\footnotetext{
${ }^{1}$ The games at Olympia started $776 \mathrm{BC}$ with only a single event, the stadium sprint. Over time they grew considerably in size, until they were finally abolished in 393 AD by the Roman emperor Theodosius.
} 
Moosa and Smith, 2004; Bernard and Busse, 2004). In addition, population size determines the pool from which potential talents can be drawn. Therefore, population size is another important factor explaining Olympic achievement (e.g. Johnson and Ali, 2000).

In the light of the results from the literature, it is helpful to think about generating Olympic success in terms of a production function, with GDP and population as proxies for actual inputs. Other factors from the literature can be seen as determinants of total factor productivity. For example, it is well known that socialist and host countries systematically outperform the others (e.g Bernard and Busse, 2004; Ball, 1972; Levine, 1974; Seppänen, 1981; Grimes et al., 1974; Johnson and Ali, 2000), and that hosting the Olympic Games considerably increases the public support for (and therefore the money and effort invested in) sports in the years before the Games. The importance given to sports in a society seems to matter. It influences the willingness of funding bodies such as the government to provide money for athletes and training facilities, the career choices of potential athletes, ${ }^{2}$ and the choice of "technology", given the resource restrictions faced by the country.

Importance of sport in society is a concept which is hard to measure. But the production function approach allows us to treat it in a way similar to technical efficiency. To illustrate this point, consider two countries with different medal shares $Y$ at the Games, country 1 outperforming country 2. This difference in performance can be due to different resource endowments or to different training technologies, but it could also reflect the fact that there is less public support for sports in country 2. The consequence would be that the actual budget available for promoting sport is lower, and that the pool from which athletes to be sent to the Games can be selected is smaller. The production frontier represents the maximum medal share for a given resource level and a given technology. In Figure 1, this medal share is $Y^{\star}$, given that the resource endowments in the two countries are the same. Both countries are below this medal share: the distance to the production frontier measures the different relative importance placed on sports by the two countries. Using stochastic frontier analysis, it is possible to empirically distinguish between the determinants of performance differences at

\footnotetext{
${ }^{2}$ Because of the weight attached to success at international competitions, athletes from communist countries received more public support and had greater incentives to excel. See Shughart and Tollison (1993) for a property rights based argument.
} 
the Olympic Games, and to isolate the effect of preferences.

Figure 1: Production of Olympic Success

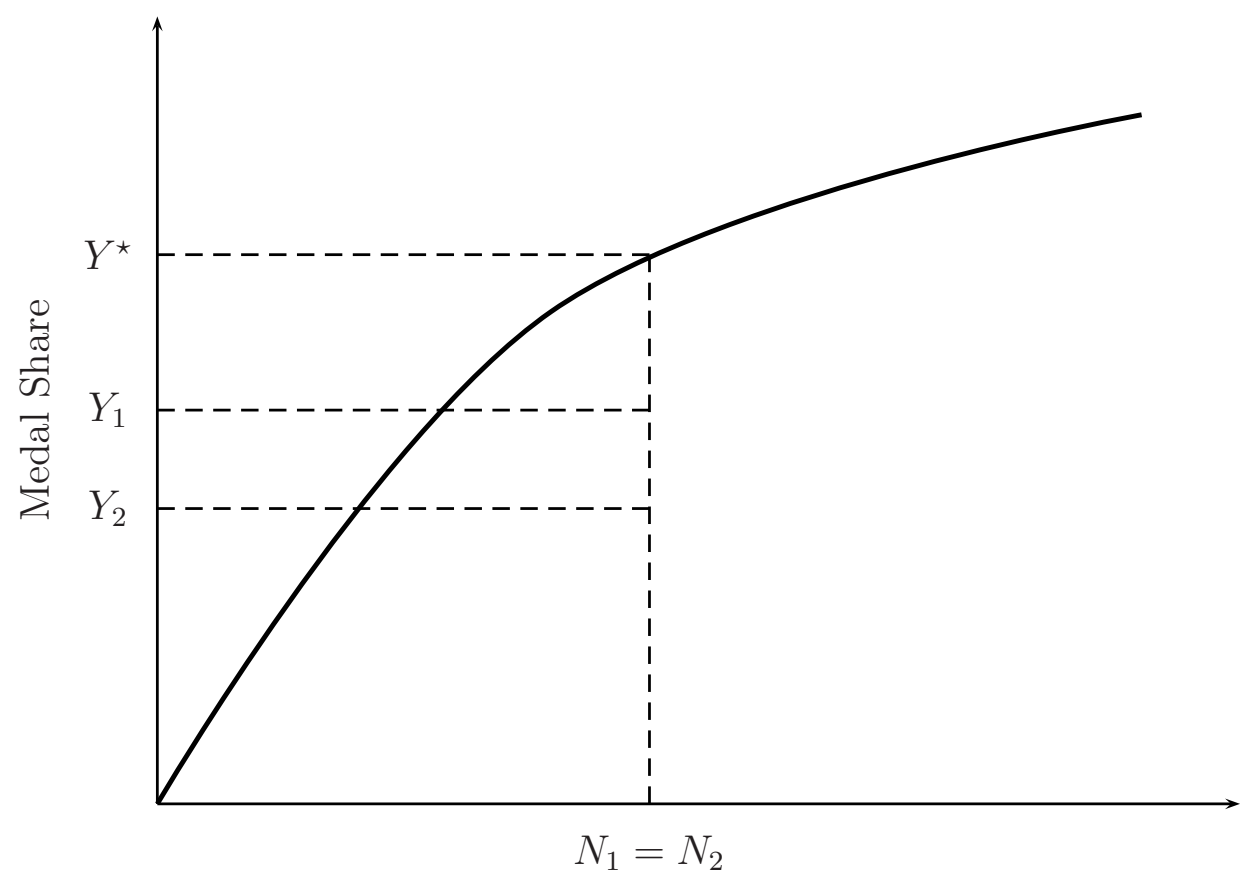

Resources

\section{Data}

The data set covers the period from the 1952 Olympic Games in Helsinki to the 2004 Games in Athens. The most commonly used measure for success at the Games is the number of medals awarded to each country. The variable $M S$ (medal share) represents the number of medals won by a country divided by the total number of medals in a given year. ${ }^{3}$ The second measure of Olympic success is broader and includes not only the medal winning countries, but also the countries with athletes who have been awarded the Olympic diploma. ${ }^{4}$ We

\footnotetext{
${ }^{3}$ We use equal weights for the medals to calculate the share (e.g. Grimes et al., 1974; Bernard and Busse, 2004). Different weighting schemes for the different colored medals have been proposed in the literature. For example, Ball (1972) uses a weighting of one point for a bronze, two points for a silver and three points for a gold medal. Moosa and Smith (2004) use the alternative weights $0.6,0.3$ and 0.1 for gold, silver and bronze. Our results are not sensitive with respect to the weighting scheme.

${ }^{4}$ Although public interest focusses mainly on the medal winning athletes, the attainment of the Olympic diploma can be very important for small countries which win only few medals or
} 
collected data for 125 disciplines which were introduced before 1976. We grouped these disciplines as follows: Cycling, gymnastics, rowing and canoeing, swimming, track and field, weightlifting and wrestling. For track and field, swimming, and gymnastics, the data allow an analysis of gender specific effects. The data source is Wallechinsky (2004) and the official web page of the 2004 Olympic Games (http://www.athens2004.com/).

The GDP and population data are from the Groningen data base ${ }^{5}$, which provides consistent and comparable GDP estimates. When necessary, we also used Maddison (2004). Thus we were able to include 131 countries in the analysis. Dummies capture host, Soviet and other planned economies effects. ${ }^{6}$

\section{Empirical Model}

The basic idea of efficiency measurement is that firms might also produce below the frontier, i.e. waste resources. The production frontier defines the maximum attainable output for a given input vector. Stochastic frontier analysis was introduced by the pioneering work of Aigner et al. (1977) and Meeusen and Van Den Broeck (1977). The method allows us to decompose deviations of actual observed output $Y$ from the estimated frontier into random deviations and inefficiency. ${ }^{7}$ Consider the model

$$
Y_{i t}=F\left(\mathbf{X}_{i t}\right) \exp \left(v_{i t}\right) T E_{i t}, i=1, \ldots, N, \quad t=1, \ldots, T,
$$

where $\mathbf{X}$ is a vector of inputs, $T E$ is the efficiency measure, and $v_{i t}$ is an error term incorporating country-specific, time variable random shocks into the analysis. Efficiency is determined by

$$
T E_{i t}=\frac{Y_{i t}}{F\left(\mathbf{X}_{i t}\right) \exp \left(v_{i t}\right)} ; 0 \leq T E_{i t} \leq 1
$$

none at all.

${ }^{5}$ Groningen Growth and Development Centre and The Conference Board, Total Economy Database, January 2005, http://www.ggdc.net

${ }^{6}$ The $S O V$ dummy includes Bulgaria, Czechoslovakia, East Germany, Hungary, Poland, USSR, Romania, through to 1988, the "Unified Team" in 1992 and Cuba over the whole period, the PLAN dummy China, North Korea, Albania, Yugoslavia (the latter two until 1988, Bernard and Busse, 2004).

${ }^{7}$ For a complete treatment of stochastic frontier analysis, see Coelli et al. (Chapters 8-10 2005) and Kumbhakar and Lovell (2000). 
Taking logs, equation (1) becomes

$$
y_{i t}=f\left(\mathbf{x}_{i t}\right)+\epsilon_{i t} ; \epsilon_{i t}=v_{i t}-u_{i t} ; T E_{i t}=\exp \left(-u_{i t}\right) ; u_{i t}>0 .
$$

The random disturbances are normally distributed, i.e. $v_{i t} \sim N\left(0, \sigma_{v}^{2}\right)$. For the Battese and Coelli (1995) specification, the distributional assumption for the one sided error $u_{i t}$ is truncated normal, $u_{i t} \sim N^{+}\left(\mu_{i t}, \sigma_{u}^{2}\right)$. Additionally it is assumed $v_{i t}$ and $u_{i t}$ are independent, and that both errors are uncorrelated with the explanatory variables $\mathbf{x}_{i t}$. Inefficiency effects can be modelled by making the expected value of the truncated distribution a linear combination of explanatory variables $\mathbf{z}_{i t}$ and a parameter vector $\boldsymbol{\delta}, u_{i t} \sim N^{+}\left(\mathbf{z}_{i t} \boldsymbol{\delta}, \sigma_{u}^{2}\right)$. We simultaneously estimate the parameters of the stochastic frontier and technical inefficiency effects with maximum likelihood. ${ }^{8}$ The likelihood function is expressed in terms of the variance parameters $\sigma^{2} \equiv \sigma_{u}^{2}+\sigma_{v}^{2}$ and $\gamma \equiv \sigma_{u}^{2} / \sigma^{2}=\sigma_{u}^{2} /\left(\sigma_{v}^{2}+\sigma_{u}^{2}\right)$, i.e. $\sigma^{2}$ is a measure of the total variance of the combined error term $\epsilon_{i t}=v_{i t}-u_{i t}$, and $\gamma$ indicates the relative importance of the two errors. Technical efficiency of country $i$ at time $t$ is $T E_{i t}=\exp \left(-u_{i t}\right)$. The prediction of technical efficiency is based on the conditional expectation: $E\left(\exp \left(-u_{i t}\right) \mid \epsilon_{i t}\right), \epsilon_{i t}=v_{i t}-u_{i t}=y_{i t}-f\left(\mathbf{x}_{i t}\right)$.

As pointed out in the introduction, our interpretation of efficiency in the context of Olympic success is importance of sports in society. Total GDP and population are used as proxies for the available resources in the 131 countries under analysis. Therefore, the measure can also reflect the (unobservable) share of total resources that countries actually choose to invest.

\section{Empirical Results}

\subsection{Medal Production}

We begin by estimating the performance of countries in the production of Olympic medals in the years 1952-2000. As functional form we use the translog production function, which is more flexible than the Cobb Douglas. ${ }^{9}$ The output is the log medal share $M S_{i t}$, GDP $\left(G D P_{i t}\right)$ and population $\left(P O P_{i t}\right)$ are used as inputs. To be able to distinguish host country and planned economy effects on impor-

\footnotetext{
${ }^{8}$ For the derivation of the likelihood function see Battese and Coelli (1993).

${ }^{9}$ The translog production function introduced by Christensen et al. (1973) is a second order approximation to an arbitrary two times differentiable production function. A likelihood ratio test rejects the Cobb Douglas specification in favour of the translog (LR: 73.82).
} 


\section{Table 1: Production Function: Medal Shares}

\begin{tabular}{lrrr}
\hline \hline & $\hat{\beta}_{j}$ & $\hat{\sigma}_{\beta_{j}}$ & t-statistic \\
\hline const & -2.45 & 0.99 & -2.48 \\
$G D P$ & -1.91 & 0.28 & -6.77 \\
$P O P$ & 1.31 & 0.30 & 4.32 \\
$0.5 \times G D P^{2}$ & 0.16 & 0.08 & 1.97 \\
$0.5 \times P O P^{2}$ & -0.23 & 0.09 & -2.51 \\
$G D P \times P O P$ & 0.07 & 0.08 & 0.77 \\
$H O S T$ & 0.94 & 0.26 & 3.64 \\
$S O V$ & 1.47 & 0.18 & 8.34 \\
$P L A N$ & 0.46 & 0.29 & 1.59 \\
$e_{G D P}$ & 0.61 & 0.04 & 13.60 \\
$e_{P O P}$ & -0.23 & 0.05 & -4.41 \\
\hline
\end{tabular}

cross sections: 108; periods: 13; Nobs: 643; Log Likelihood: -8393.07

tance of sports and production technology as well as for systematic differences in the resources allocated to sports, we include the dummies in both the production function and the inefficiency component. The stochastic frontier production function to be estimated is

$$
\begin{aligned}
& \begin{array}{l}
\ln \left(M S_{i t}\right) \\
=\beta_{0}+\beta_{1} \ln \left(G D P_{i t}\right)+\beta_{2} \ln \left(P O P_{i t}\right)+\beta_{3} 0.5 \ln \left(G D P_{i t}\right)^{2}+\beta_{4} 0.5 \ln \left(P O P_{i t}\right)^{2}+ \\
\quad+\beta_{5} \ln \left(G D P_{i t}\right) \ln \left(P O P_{i t}\right)+\beta_{6} H O S T_{i t}+\beta_{7} S O V_{i t}+\beta_{8} P L A N_{i t}+v_{i t}-u_{i t},
\end{array} \\
& v_{i t} \sim N\left(0, \sigma_{v}^{2}\right) \text { and } u_{i t} \sim N^{+}\left(\mu_{i t}, \sigma_{u}^{2}\right) .
\end{aligned}
$$

The technical inefficiency effect is modelled as

$$
\mu_{i t}=\delta_{1} H O S T_{i t}+\delta_{2} S O V_{i t}+\delta_{3} P L A N_{i t}
$$

The estimation results are reported in Table 1.

The results show that a host country on the frontier can achieve a medal share which is 156 percent greater than for normal participation. The effect for the Soviet countries is a potential medal share 4.35 times that of a comparable market economy. The elasticities for the translog are given by

$$
\begin{aligned}
& e_{G D P}=\beta_{1}+\beta_{3} \ln (G D P)+\beta_{5} \ln (P O P), \\
& e_{P O P}=\beta_{2}+\beta_{4} \ln (P O P)+\beta_{5} \ln (G D P) .
\end{aligned}
$$


The standard deviations can be calculated using the delta method (e.g. Greene, 2003). Table 1 shows the production elasticities evaluated at the sample means. The elasticity for GDP has the expected positive sign: an increase of GDP by 1 percent leads to an increase in the medal share by 0.61 percent. The estimated elasticity for population has a negative sign.

To explain this unexpected result, we group the countries by GDP per capita. "Rich" countries are countries with GDP per capita above sample average, and "poor" countries are below average. We focus on the range of income and population given by the 25 percent and the 75 percent quantile. For rich countries, the limits of this range are given by 11 and 13 for $\ln G D P$, for $\ln P O P$, they are 8 and 10. For the poor countries the ranges are in between 10 and 12 for $\ln G D P$ and 9 and 11 for $\ln P O P$. The boxes in Table 2 show the elasticities for the respective ranges. The elasticities for GDP are always positive as expected. The results for population, however, are different. Only very rich countries with relatively small populations can gain from an population increase, which is reasonable: for poor countries, a population increase reduces resources available for producing Olympic success.

The estimation results for the inefficiency effect are presented in Table 3. A likelihood ratio test rejects the null hypothesis of the absence of inefficiency effects $\left(H_{0}: \delta_{1}=\delta_{2}=\delta_{3}=\sigma_{u}=0\right.$.) The test statistic has a mixed $\chi^{2}$ distribution with four degrees of freedom and the critical value as tabulated in Table 1 in Kodde and Palm (1986) is 12.48. Since $\gamma$ is a measure for the relative contribution of both errors, it is possible to conclude that deviations from the frontier are due to noise as well as differences with respect to the importance of sports. The negative sign of the dummies indicates that host and non-market-economy countries value sports higher than the other countries.

In Figure 2 box plots of the estimated efficiencies are displayed for each event in the period 1952-2000. Comparing the U.S. and the USSR, an interesting result emerges: although the U.S. has been about equally successful if the total number of medals is considered, our measure indicates that sports is more important in the Soviet society without exception. After the collapse of the Soviet Union, the Unified Team ${ }^{10}$ in 1992 was still performing better, but a considerable perfor-

\footnotetext{
${ }^{10}$ The Unified Team consisted of 12 of the 15 former Soviet republics competing together for the last time in Barcelona. The Baltic republics of Estonia, Latvia and Lithuania participated with separate teams.
} 
Table 2: Production Elasticities

\begin{tabular}{|c|c|c|c|c|c|c|c|}
\hline \multirow{2}{*}{\multicolumn{2}{|c|}{ DP }} & \multicolumn{6}{|c|}{ POP } \\
\hline & & 7 & 8 & 9 & 10 & 11 & 12 \\
\hline \multirow{6}{*}{$e_{G D P}$} & 9 & 0.03 & 0.09 & 0.16 & 0.22 & 0.29 & 0.35 \\
\hline & 10 & 0.19 & 0.26 & 0.32 & 0.39 & 0.45 & 0.52 \\
\hline & 11 & 0.36 & 0.42 & 0.49 & 0.55 & 0.62 & 0.68 \\
\hline & 12 & 0.52 & 0.59 & 0.65 & 0.72 & 0.78 & 0.85 \\
\hline & 13 & 0.69 & 0.75 & 0.82 & 0.88 & 0.95 & 1.01 \\
\hline & 14 & 0.85 & 0.92 & 0.98 & 1.05 & 1.11 & 1.18 \\
\hline \multirow{6}{*}{$e_{P O P}$} & 9 & 0.26 & 0.03 & -0.21 & -0.44 & -0.67 & -0.91 \\
\hline & 10 & 0.33 & 0.09 & -0.14 & -0.38 & -0.61 & -0.84 \\
\hline & 11 & 0.39 & 0.16 & -0.08 & -0.31 & -0.54 & -0.78 \\
\hline & 12 & 0.46 & 0.22 & -0.01 & -0.24 & -0.48 & -0.71 \\
\hline & 13 & 0.52 & 0.29 & 0.05 & -0.18 & -0.41 & -0.65 \\
\hline & 14 & 0.59 & 0.35 & $\overline{0.12}$ & -0.11 & -0.35 & -0.58 \\
\hline
\end{tabular}

Notes:

The column headers are the ranges of the $\log$ of $P O P$, and the row headers the log of $G D P$. The thin (bold) boxes show elasticities for the interquartile ranges for rich (poor) countries. "Rich" countries are countries with GDP per capita above sample average, and "poor" countries are below average.

mance decrease can be observed for the team of the Russian Federation in 1996 and 2000. For the U.S., the measure normally lies between the median and the upper quartile. There are, however, two exceptions, the years 1984 and 1996 when the Games were held in the U.S. - an example for the host country effect and the changing attitude towards sports. An even more striking example for this effect is Mexico. Although the performance is rather poor over the years, there is a huge increase in 1968 when the Olympic Games were hosted in Mexico City.

Figure 3 displays the results for the German speaking countries. In 1952, only a West German team participated, with a measure around the upper quartile. In 1956, East German athletes participated, but the IOC forced East and West Germany to field a joint team for these and the following two Olympic Games. The performance of the joint team does not differ very much from that of West Germany in 1952, which remains almost constant over the whole period, with the exception of the Olympic Games in Munich in 1972. The fact that the GDR was allowed to field its own team in 1968 leads to an astonishing increase 
Table 3: Importance of Sports

\begin{tabular}{lrrr}
\hline \hline & $\hat{\beta}_{j}$ & $\hat{\sigma}_{\beta_{j}}$ & t-statistic \\
\hline HOST & -1.79 & 0.54 & -3.31 \\
SOV & -4.40 & 1.54 & -2.87 \\
PLAN & -4.49 & 2.57 & -1.75 \\
$\sigma^{2}$ & 1.20 & 0.19 & 6.48 \\
$\gamma$ & 0.47 & 0.15 & 3.05 \\
\hline
\end{tabular}

$L R: 17.519 ;$ restrictions: 4

cross sections: 108; periods: 13; Nobs: 643

in performance. After only four years, East Germany jumps to the top in the ranking and remains there until Seoul $1988 .{ }^{11}$ It does not seem that the reunited Germany has been able to benefit from the successful East German athletes: in 1992, the measure drops back to the "standard" German level. For Austria and Switzerland the implication is that the value of sports represented in the Summer Olympic Games is not very high in either society. The drop in performance of Switzerland in 1956 is due to the departure of the Swiss team after a few days. The Swiss joined the boycott of the Netherlands and Spain in reaction to the repression of the Hungarian uprising by the Soviets. ${ }^{12}$

\subsection{Sport and Gender}

Are there differences in the importance of sports across disciplines and gender? To address this issue, we use the data set with the first 8 ranked athletes for cycling, gymnastics, rowing and canoeing, swimming, track and field, weightlifting and wrestling. For track and field, swimming, and gymnastics, data for both genders are available. The output measure is now the log share of points won by each country in each sport by gender. To compare importance, we use a version of the Battese and Coelli (1995) model with time invariant efficiency. The stochastic

\footnotetext{
${ }^{11}$ Seppänen (1981) argues that a possible explanation for East German dominance is that it was the only combination of a protestant and communist country.

${ }^{12}$ In addition, the Games in Melbourne were boycotted by Cambodia, Egypt, Iraq, and Lebanon because of the Suez crisis.
} 
Table 4: Production Function Point Shares: Sports and Gender

\begin{tabular}{lrrr}
\hline \hline & $\hat{\beta}_{j}$ & $\hat{\sigma}_{\beta_{j}}$ & $t$-statistic \\
\hline const & -3.99 & 0.96 & -4.16 \\
$P O P$ & -0.05 & 0.23 & -0.21 \\
$G D P$ & 0.09 & 0.18 & 0.50 \\
$0.5 \times P O P^{2}$ & -0.22 & 0.06 & -3.65 \\
$0.5 \times G D P^{2}$ & -0.18 & 0.04 & -4.29 \\
$G D P \times P O P$ & 0.21 & 0.05 & 4.33 \\
HOST & 0.39 & 0.06 & 6.31 \\
SOV & 0.49 & 0.05 & 9.48 \\
PLAN & -0.26 & 0.16 & -1.66 \\
$e_{G D P}$ & 0.09 & 0.05 & 1.92 \\
$e_{P O P}$ & 0.17 & 0.05 & 3.17 \\
$\sigma^{2}$ & 0.75 & 0.05 & 13.97 \\
$\gamma$ & 0.56 & 0.02 & 24.75 \\
$\mu$ & 1.29 & 0.09 & 14.1 \\
\hline
\end{tabular}

$L R: 996.44$; restrictions: 2

cross sections: 507; periods: 14; Nobs: 2746; Log Likelihood: -2873.5

frontier production function to be estimated is ${ }^{13}$

$$
\begin{aligned}
& \ln \left(P S_{i t}\right)=\beta_{0}+\beta_{1} \ln \left(G D P_{i t}\right)+\beta_{2} \ln \left(P O P_{i t}\right)+\beta_{3} 0.5 \ln \left(G D P_{i t}\right)^{2}+\beta_{4} 0.5 \ln \left(P O P_{i t}\right)^{2}+ \\
&+\beta_{5} \ln \left(G D P_{i t}\right) \ln \left(P O P_{i t}\right)+\beta_{6} H O S T_{i t}+\beta_{7} S O V_{i t}+\beta_{8} P L A N_{i t}+v_{i t}-u_{i} ; \\
& v_{i t} \sim N\left(0, \sigma_{v}^{2}\right) \text { and } u_{i} \sim N^{+}\left(\mu, \sigma_{u}^{2}\right) .
\end{aligned}
$$

The subscript $i$ now denotes a country, sport, and gender specific unit, e.g. U.S., track and field, male. The estimation results are displayed in Table 4.

Evaluated at the sample means, the effects of population and GDP on the point share are positive. ${ }^{14}$ An increase in GDP by one percent leads to an increase in the point share by 0.09 percent, for population it is 0.17 percent. The fully efficient HOST and $S O V$ countries have the advantage of a point share which is 50 to 60 percent higher, while the other planned economies can only win 75 percent. The likelihood ratio test rejects the null of a symmetric error at all conventional levels. ${ }^{15}$ Figure 4 shows box plots for the estimated efficiency

\footnotetext{
${ }^{13}$ Again, the Cobb Douglas specification is rejected in favour of the translog ( $\left.L R: 57.01\right)$.

${ }^{14}$ Calculating the elasticities for the entire range of $G D P$ and $P O P$ as in Table 2, we again find the negative impact of $P O P$ for relatively poor countries with high populations.

${ }^{15}$ The critical value from Kodde and Palm (1986) is 8.27.
} 
for the seven groups. With respect to swimming results, the U.S. perform better than the Soviet Union for both men and women, while the opposite is true for gymnastics. In rowing and wrestling the relative performance is rather even. Obviously, importance of sports is not equal across disciplines for a given country. Countries seem to specialize in different sports. ${ }^{16}$

An extreme example for this is the case of Mongolia. Although in most disciplines Mongolia has never been able to reach the top ranks, there is the exception of weightlifting and wrestling. From 1952 to 1992, athletes from this country won 31 medals and Olympic diplomas. Compared to the performance of the Soviet Union and the US in the same period, this does not seem exceptionally successful (Soviet Union: 138 medals and diplomas, USA: 103 medals and diplomas). But the efficiency distribution demonstrates the weight attached to this particular sport in Mongolia: given the resource endowment, the country is much more efficient in producing Olympic success than the US and the Soviet Union, in fact, it is the most efficient producer. In contrast, Mexico does not seem to have specialized in any of the sports in the data set.

The performance of the U.S. with respect to track and field for men is outstanding: the measure is twice as high as for the Soviet Union. For women, on the other hand, the Soviet Union performs slightly better. A similar pattern can be seen in the results displayed in Figure 5. The West German male track and field athletes outperformed their eastern counterparts, while the opposite is true for women. An even clearer picture emerges for swimming: the West German male swimmers were superior to East German men, while the East German women were superior to their counterparts in the West. A possible explanation for this finding could be that communist countries have been more successful than market economies in providing women equal access to sporting activities. ${ }^{17}$ Specialization is again apparent: while the GDR is especially efficient in gymnastics, it is cycling for West Germany.

\footnotetext{
${ }^{16}$ Tcha and Pershin (2003) analyze the issue of specialization using the concept of revealed comparative advantage from international trade theory.

${ }^{17}$ This point has also been made by Seppänen (1981).
} 


\section{Conclusion}

Based on a rich data set which makes it possible to distinguish effects by sports and gender, we estimate the importance of sports in society using a measure of technical efficiency in the production of Olympic success. The translog specification reproduces the results from the literature: GDP is a good predictor of success for both output measures (medal shares and point shares). The effect of population, however, is positive only for relatively rich countries. This observation might help to explain the mixed outcome in the literature concerning population effects (e.g. Ball, 1972; Bernard and Busse, 2004; Levine, 1974; Johnson and Ali, 2000).

The second contribution is the interpretation of technical efficiency as a measure for the value of sports in a society. After controlling for systematic differences in the resources allocated to sports due to host and socialist effects, we still find that the spread of the importance of sports is very wide across countries, gender, and disciplines. Host and Soviet Countries not only outperform the other participants in absolute terms, given the same amount of available resources - they are also closer to their individual frontiers.

The official webpage of the Chinese Olympic Committee (en.olympic.cn) provides an overview of 4,000-10,000 years history of sports in China, with a focus on weightlifting, archery, wrestling and equestrianism. Given that in terms of gold medals the country reached third rank behind the U.S. and Russia in Sidney 2000, and second rank behind the U.S. in Athens 2004, it is likely that it will outperform the other countries in Beijing 2008. Our results show that this is not only due to resources available to create Olympic success, but also to the importance of sports in society. 
Figure 2: The production of Olympic medals, 1952-2000.

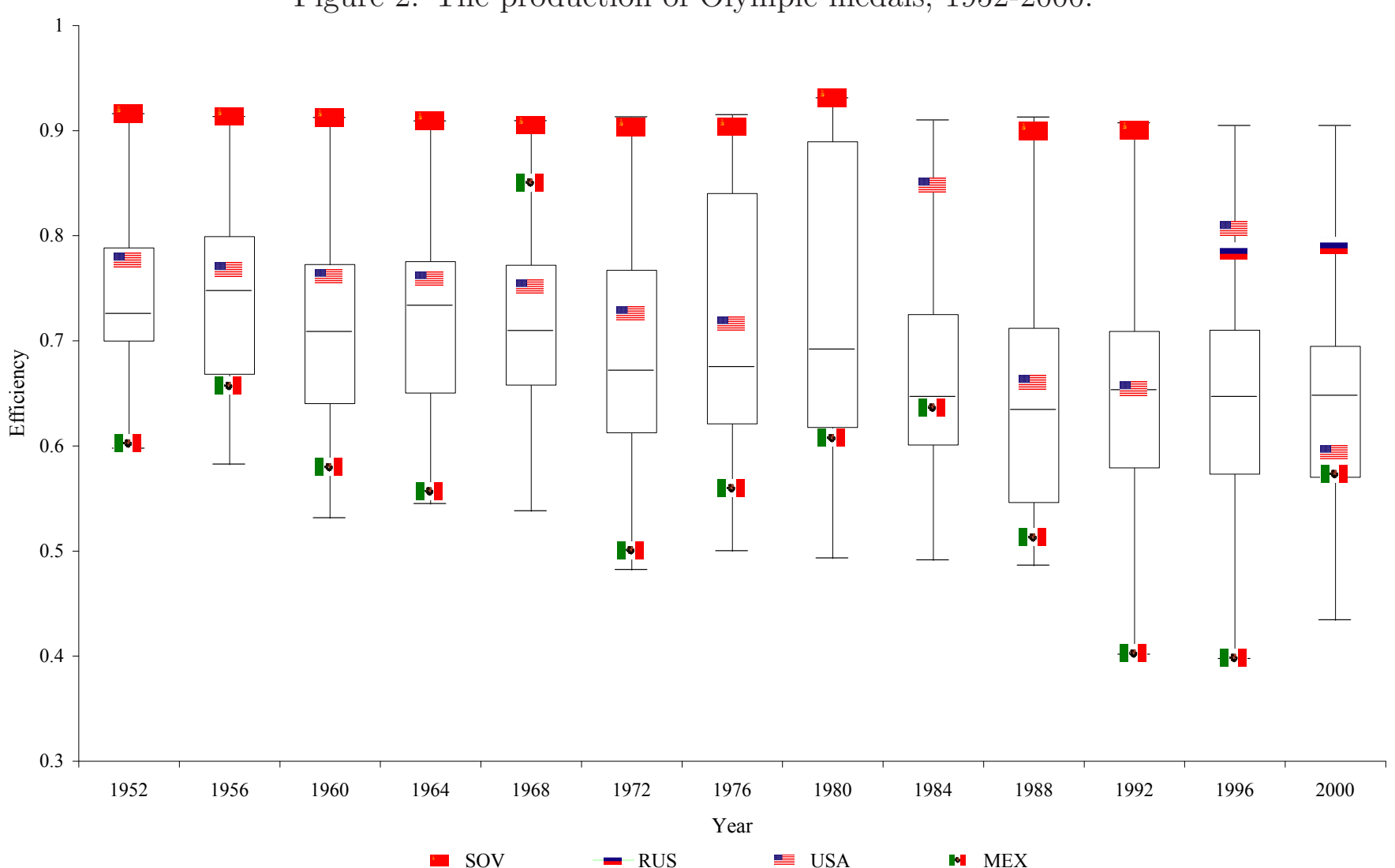


Figure 3: The production of Olympic medals, 1952-2000.

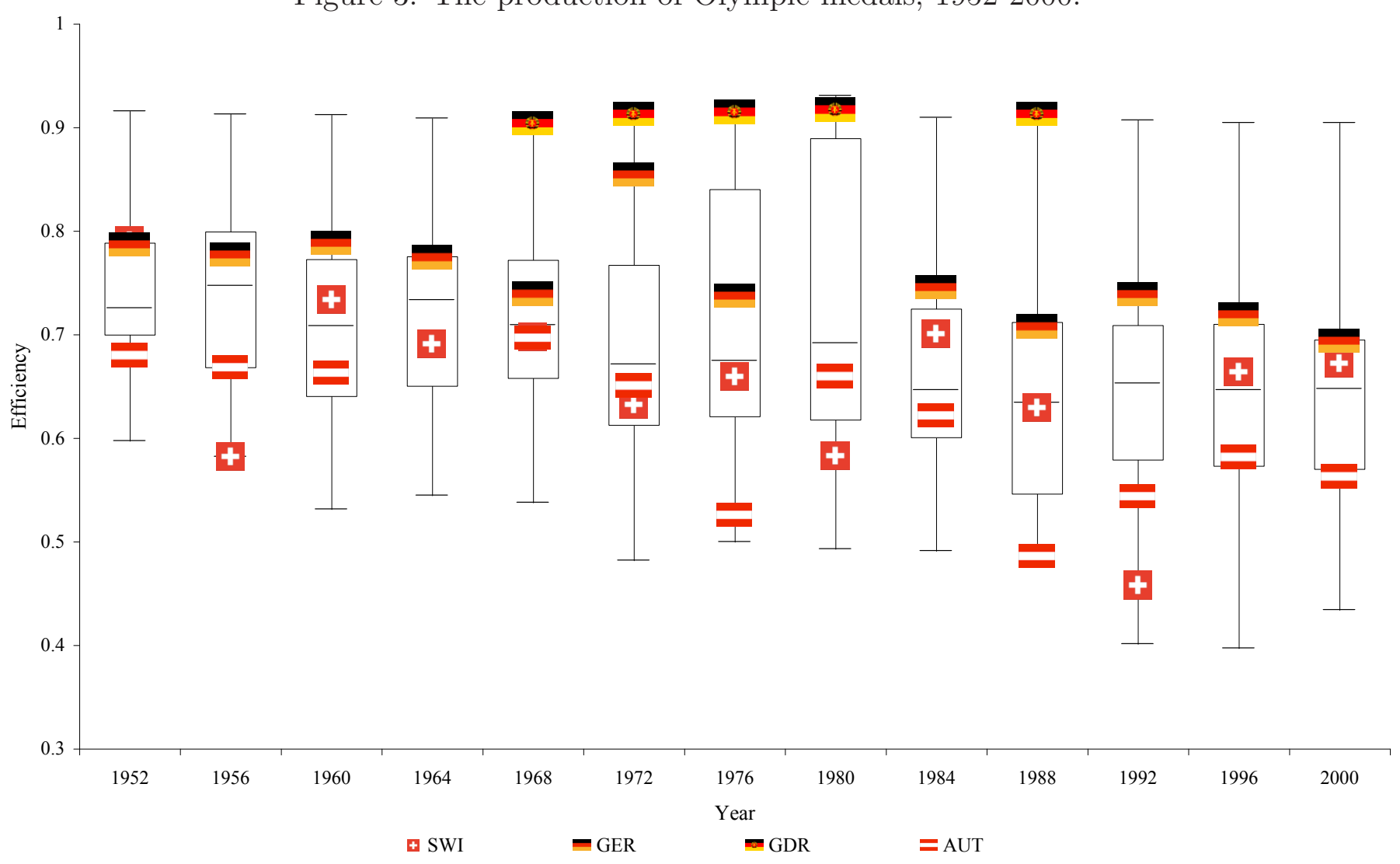


Figure 4: Sports and Gender Specific Performance

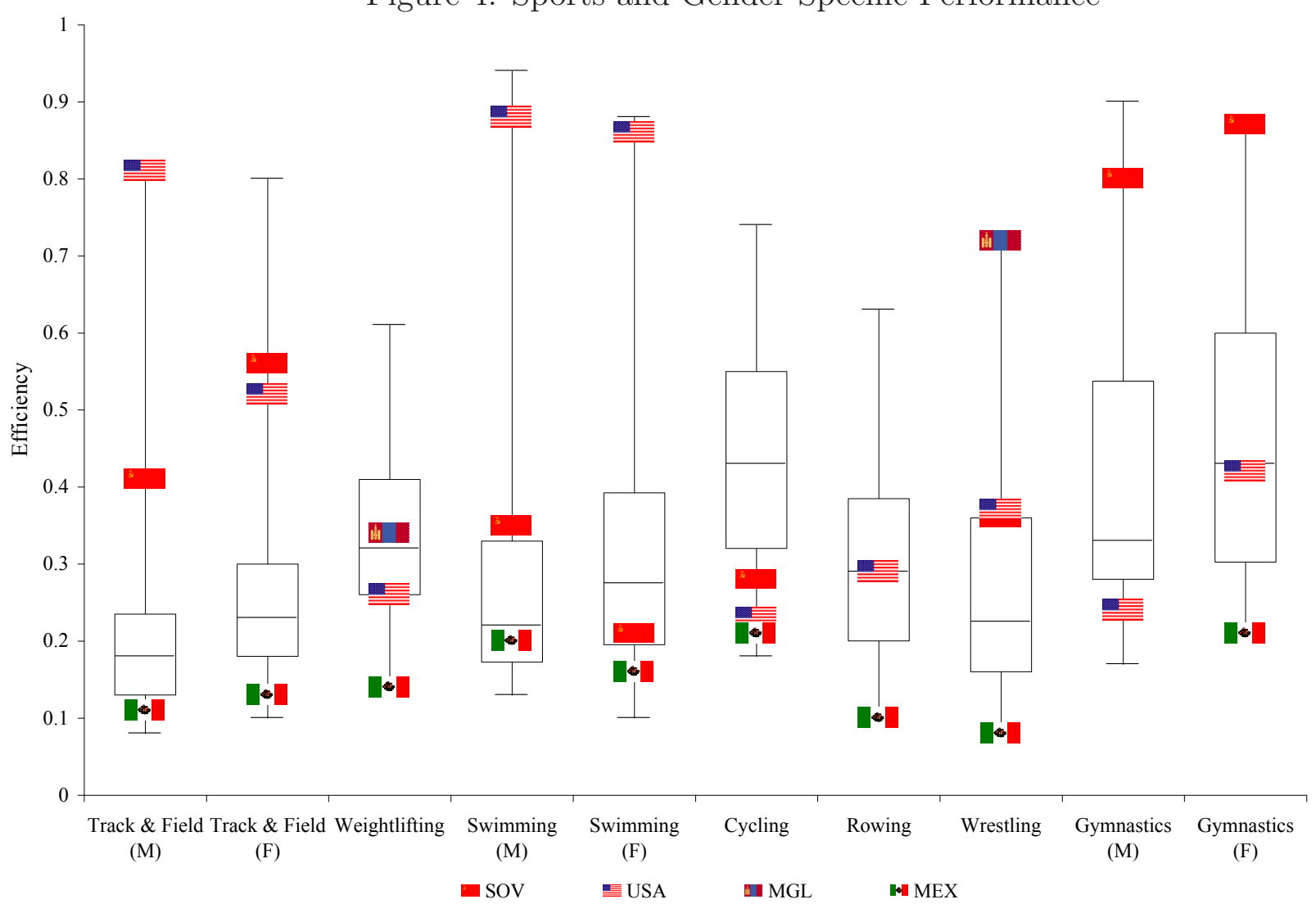


Figure 5: Sports and Gender Specific Performance

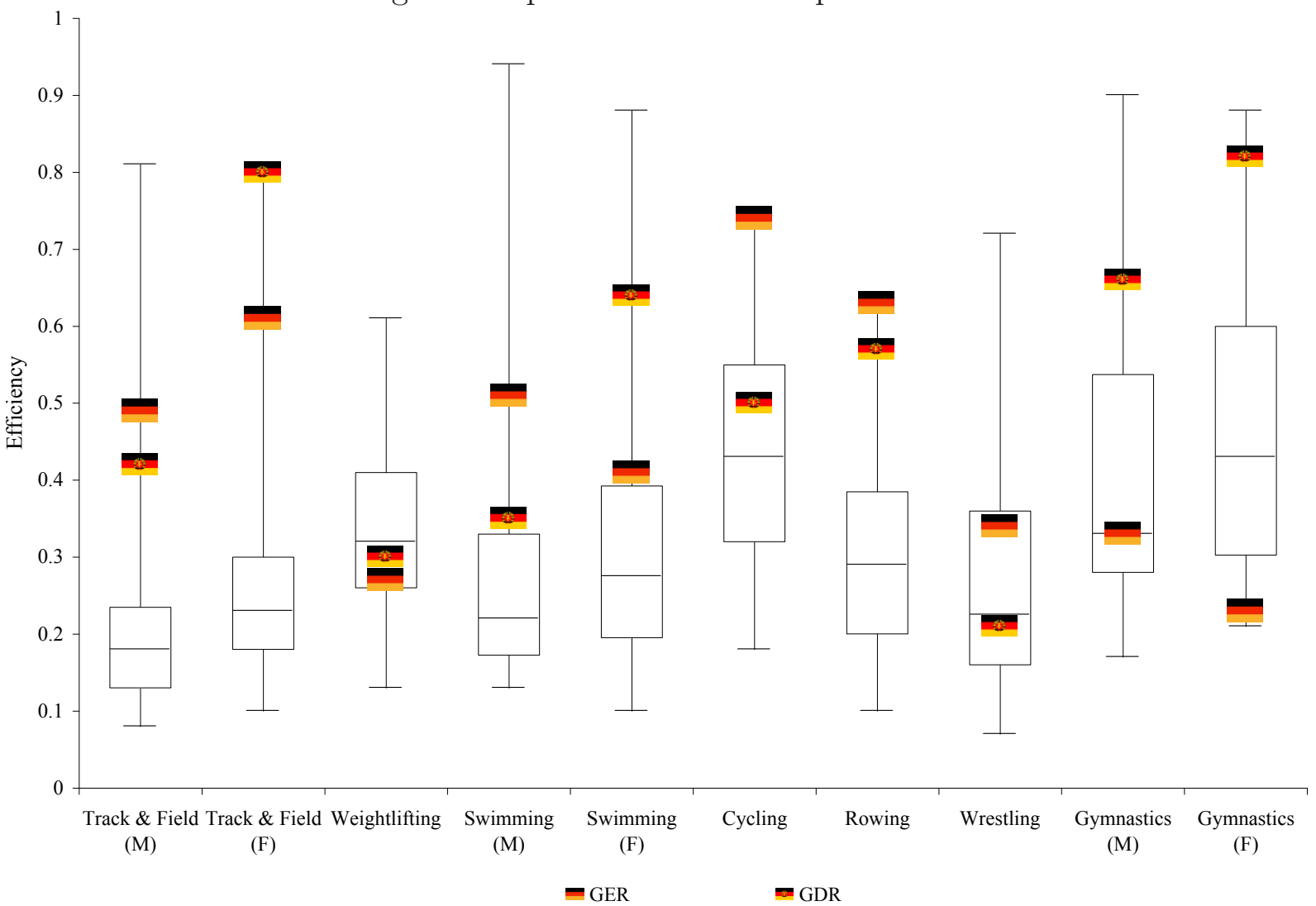




\section{References}

Aigner, D., Lovell, C., and Schmidt, P. (1977), "Formulation and Estimation of Stochastic Frontier Production Function Models." Journal of Econometrics $\mathbf{6}$, $21-37$.

Ball, D. W. (1972), "Olympic Games Competition: Stuctural Correlates of National Success." International Journal of Comparative Sociology 13, 186-200.

Battese, G. E. and Coelli, T. J. (1993), "A Stochastic Frontier Production Function Incorporating a Model for Technical Inefficiency Effects.", working Papers in Econometrics and Applied Studies No 69, Department of Econometrics, University of New England, Armidale.

Battese, G. E. and Coelli, T. J. (1995), "A Model for Technical Inefficicency Effects in a Stochastic Frontier Production Function for Panel Data." Empirical Economics 20, 325-332.

Bernard, A. B. and Busse, M. R. (2004), "Who Wins the Olympics: Economic Resources and Medal Totals." Review of Economics and Statistics 86, 413-417.

Christensen, L. R., Jorgenson, D. W., and Lau, L. J. (1973), "Transcendental Logarithmic Production Frontiers." Review of Economics and Statistics 55, $28-45$.

Coelli, T. J., Rao, D. S. P., O'Donnel, C., and Battese, G. E. (2005), An Introduction to Efficiency and Productivity Analysis. 233 Spring Street, New York, NY 10013, USA: Springer Science and Business Media, Inc.

Greene, W. H. (2003), Econometric Analysis. Fifth ed., London, New York, Tokyo: Prentice Hall.

Grimes, R. A. J., Kelly, W. J., and Rubin, P. H. (1974), "A Socioeconomic Model of National Olympic Performance." Social Science Quarterly 55, 777-200.

Johnson, D. K. N. and Ali, A. (2000), "Coming to Play or Coming to Win: Participation and Success at the Olympic Games.", wellesly College Working Paper. 
Jokl, E., Karvonen, M. J., Kihlberg, J., Koskela, A., and Noro, L. (1956), Sports in the Cultural Pattern of the World: A Study of the Olympic Games 1952 at Helsinki. Helsinki, Finland: Institute of Occupational Health.

Kodde, D. A. and Palm, F. (1986), "Wald Criteria for Jointly Testing Equality and Inequality Restrictions." Econometrica 54, 1243-1248.

Kumbhakar, S. C. and Lovell, C. A. K. (2000), Stochastic Frontier Analysis. Cambridge: Cambridge University Press.

Levine, N. (1974), "Why Do Countries Win Olympic Medals? Some Structural Correlates of Olympic Games Success:1972." Sociology and and Social Research 58, 353-360.

Maddison, A. (2004), The World Economy: Historical Statistics. OECD.

Meeusen, W. and Van Den Broeck, J. (1977), "Efficiency Estimation from CobbDouglas Production Functions with Composed Error." International Economic Review 18, 435-444.

Moosa, I. A. and Smith, L. (2004), "Economic Development Indicators as Determinants of Medal Winning at the Sydney Olympics: An Extreme Bound Analysis." Australian Economic Papers 288-301.

Novikov, A. D. and Maksimenko, M. (1973), "Soziale und Ökonomische Faktoren und Das Niveau Sportlicher Leistungen Verschiedener Länder." Sportwissenschaft 2, 156-167.

Seppänen, P. (1981), "Olympic Success: A Cross-National Perspective." In: G. R. F. Lüschen and G. H. Sage (Eds.), Handbook of Social Science of Sport, 93-116, Champaign, Illinois: Stipes Publishing Company.

Shughart, W. F. and Tollison, R. D. (1993), "Going for Gold: Property Rights and Athletic Effort in Transitional Economies." Kyklos 46, 263-272.

Tcha, M. and Pershin, V. (2003), "Reconsidering Performance at the Summer Olympics and Revealed Comparatrive Advantage." Journal of Sports Economics 4, 216-239. 
Wallechinsky, D. (2004), The Complete Book of the Olympics: 2004 Edition. London: Aurum Press Ltd. 